\title{
Anti-inflammatory effects of Daehwangmokdantang, a traditional herbal formulation, in lipopolysaccharide-stimulated RAW 264.7 macrophages
}

\author{
MOON HEE LEE ${ }^{1,2 *}$, SU HYUN HONG ${ }^{1 *}$, CHEOL PARK $^{3}$, MIN-HO HAN ${ }^{4}$, SUNG OK KIM $^{5}$, \\ SANG HOON HONG ${ }^{6}$, GI-YOUNG KIM ${ }^{7}$ and YUNG HYUN CHOI ${ }^{1,2}$
}

${ }^{1}$ Department of Biochemistry, Dongeui University College of Korean Medicine, Busan 614-052; ${ }^{2}$ Anti-Aging Research Center and Blue-Bio Industry RIC; ${ }^{3}$ Department of Molecular Biology, College of Natural Sciences and Human Ecology, Dongeui University, Busan 614-714; ${ }^{4}$ Natural Products Research Team, National Marine Biodiversity Institute of Korea, Seocheon 325-902; ${ }^{5}$ Department of Food Science and Biotechnology, College of Engineering, Kyungsung University, Busan 608-736; ${ }^{6}$ Department of Internal Medicine, Dongeui University College of Korean Medicine, Busan 614-052; ${ }^{7}$ Laboratory of Immunobiology, Department of Marine Life Sciences, Jeju National University, Jeju 690-756, Republic of Korea

Received March 6, 2016; Accepted August 17, 2017

DOI: $10.3892 / \mathrm{etm} .2017 .5296$

\begin{abstract}
Daehwangmokdantang (DHMDT) is a traditional polyherbal formulation that has known antidiarrheal and anti-inflammatory activities. However, the underlying mechanisms of these activities are poorly understood. In the present study, the inhibitory effects of DHMDT on the production of proinflammatory mediators and cytokines in lipopolysaccharide (LPS)-stimulated RAW 264.7 macrophages were investigated. The inhibitory effects of DHMDT on LPS-induced nitric oxide $(\mathrm{NO})$, prostaglandin $(\mathrm{PG}) \mathrm{E}_{2}$, tumor necrosis factor (TNF)- $\alpha$ and interleukin (IL)-1 $\beta$ production were examined using Griess reagent and ELISA detection kits. The effects of DHMDT on the expression of inducible NO synthase (iNOS), cyclooxygenase (COX)-2, IL-1 $\beta$ and TNF- $\alpha$, and their upstream signal proteins, including nuclear factor $(\mathrm{NF})-\kappa \mathrm{B}$, mitogen-activated protein kinases (MAPKs) and RAC- $\alpha$ serine/threonine-protein kinase (Akt), a phosphatidylinositol 3-kinase (PI3K) downstream effector, were investigated using western blotting and immunofluorescence staining. The results revealed the pretreatment with DHMDT significantly inhibited the LPS-induced production of NO, $\mathrm{PGE}_{2}, \mathrm{TNF}-\alpha$, and IL-1 $\beta$, and expression of iNOS, COX-2 TNF- $\alpha$, and IL- $1 \beta$,
\end{abstract}

Correspondence to: Dr Yung Hyun Choi,Department of Biochemistry, Dongeui University College of Korean Medicine, Yangjeong-dong San 45, Busanjin-gu, Busan 614-052, Republic of Korea

E-mail: choiyh@deu.ac.kr

*Contributed equally

Key words: Daehwangmokdantang, RAW 264.7 macrophages, inflammation, nuclear factor- $\kappa \mathrm{B}$, phosphatidylinositol 3-kinase, RAC- $\alpha$ serine/threonine-protein kinase, mitogen-activated protein kinases without any significant cytotoxicity. DHMDT also efficiently prevented the translocation of the $\mathrm{NF}-\kappa \mathrm{B}$ subunit $\mathrm{p} 65$ into the nucleus by interrupting the activation of the upstream mediator inhibitor of $\mathrm{NF}-\kappa \mathrm{B}$ kinase $\alpha / \beta$. Furthermore, the anti-inflammatory effects of DHMDT were associated with the suppression of LPS-induced phosphorylation of Akt and MAPKs in RAW 264.7 macrophages. Therefore, the results of the present study indicate that DHMDT exhibited anti-inflammatory activity via the inhibition of proinflammatory mediators and cytokines, in which the inactivation of $\mathrm{NF}-\kappa \mathrm{B}, \mathrm{PI} 3 \mathrm{~K} / \mathrm{Akt}$, and MAPKs may be involved. These results suggest that DHMDT may be a potential anti-inflammatory drug candidate.

\section{Introduction}

Inflammation is a complex event involving the activation of physiological and pathological immune system processes $(1,2)$. In the normal state, proinflammatory mediators, such as nitric oxide (NO) and prostaglandin $(\mathrm{PG}) \mathrm{E}_{2}$, and proinflammatory cytokines generated from macrophage cells serve an essential role in host survival and tissue repair $(1,2)$. However, when macrophages are activated by specific stimuli, these proinflammatory mediators and cytokines are overproduced, leading to various inflammatory diseases, such as arthritis, inflammatory bowel disease and asthma $(3,4)$. Therefore, inhibition of macrophage activation has been suggested as a potential therapeutic mechanism for mitigating the progression of inflammatory diseases.

Lipopolysaccharide (LPS)-induced activation of RAW 264.7 macrophages is a well-established model of inflammation, with previous studies demonstrating that LPS, a cell wall component of gram-negative bacteria, activates macrophages to produce proinflammatory mediators and cytokines, thereby mimicking an inflammatory reaction $(5,6)$. Studies have also shown that the LPS-induced stimulation of macrophages initiates the toll-like receptor (TLR)-4/myeloid 
differentiation primary response gene 88 signaling pathway, which involves the activation of nuclear factor $(\mathrm{NF})-\kappa \mathrm{B}$, phosphatidylinositol 3-kinase (PI3K)/RAC- $\alpha$ serine/threonine-protein kinase (Akt) and mitogen-activated protein kinase (MAPK) signaling pathways $(7,8)$. This, in turn, has been indicated to upregulate proinflammatory cytokines and inducible enzymes, such as inducible NO synthase (iNOS) and cyclooxygenase (COX)-2 (9,10).

The transcription factor $\mathrm{NF}-\kappa \mathrm{B}$ plays a major role in the regulation of genes associated with inflammation $(11,12)$. The activation of $\mathrm{NF}-\kappa \mathrm{B}$ occurs via phosphorylation and degradation of the suppressor protein inhibitor of $\mathrm{NF}-\kappa \mathrm{B} \alpha(\mathrm{I} \kappa \mathrm{B} \alpha)$ bound to $N F-\kappa B$, resulting in the translocation of $N F-\kappa B$ into the nucleus and the promotion and induction of the expression of various inflammatory genes $(11,12)$. TLR4-mediated signaling leads to rapid activation of the PI3K/Akt pathway, which has an important role in the regulation of LPS-induced acute inflammatory responses $(5,6)$. Previous studies have indicated that the PI3K/Akt signaling pathway contributes to TLR4-mediated NF- $\mathrm{B}$ activation and cytokine release $(7,8)$. Studies have also demonstrated that MAPKs, such as extracellular signal-regulated kinase (ERK), c-Jun NH2-terminal kinase (JNK) and p38 MAPK, function as a group of signaling molecules that are critical in relaying inflammatory information $(13,14)$. The TLR4-induced activation of MAPKs has been shown to activate the nuclear translocation of $\mathrm{NF}-\kappa \mathrm{B}$ and to culminate in the initiation of proinflammatory responses $(7,8)$. Thus, inhibition of the $\mathrm{NF}-\kappa \mathrm{B}, \mathrm{PI} 3 \mathrm{~K} / \mathrm{Akt}$ and MAPK signaling pathways is critical in combating the actions of anti-inflammatory molecules.

Daehwangmokdantang (DHMDT) is a traditional polyherbal formulation that has been used since ancient times in Korea. As described in the Donguibogam, an ancient Korean medical book published in the early 17 th century (15), DHMDT is composed of five medicinal herbs: Paeonia suffruticosa Andr., Prunus persica (L.) Batsch, Trichosanthes kirilowii Maxim, Rheum plamatum L. and mirabilite. DHMDT has been used to treat patients with digestive tract cancers and to prevent diarrhea and inflammation (15). Despite the valuable clinical effects of DHMDT on patients, the molecular mechanism of its pharmacological effects has yet to be elucidated. As part of the present research group's search for novel biologically active substances from traditional medicinal resources that are able to prevent and treat inflammation, the inhibitory effect of DHMDT on LPS-induced inflammatory responses induced in RAW 264.7 macrophages was evaluated in the present study. For the first time, to the best of our knowledge, whether DHMDT inhibits inflammatory responses via suppression of the NF- $\kappa \mathrm{B}, \mathrm{PI} 3 \mathrm{~K} / \mathrm{Akt}$, and MAPK signaling pathways was also examined.

\section{Materials and methods}

Materials and reagents. Dulbecco's modified Eagle's medium (DMEM) and fetal bovine serum (FBS) were purchased from WelGENE Inc. (Daegu, South Korea). LPS (Escherichia coli Serotype 055:B5), MTT and Griess reagent were obtained from Sigma-Aldrich (Merck KGaA, Darmstadt, Germany). $\mathrm{PGE}_{2}$ (cat. no. KGE004B) tumor necrosis factor (TNF)- $\alpha$ (cat. no. MTA00B) and interleukin (IL)-1ß (cat. no. MLB00C)
Table I. Components and their quantities in the Daehwangmokdantang decoction.

\begin{tabular}{lc}
$\begin{array}{l}\text { Component } \\
\text { (pharmacognostic nomenclature) }\end{array}$ & $\begin{array}{r}\text { Quantity of raw } \\
\text { material, g (\%) }\end{array}$ \\
\hline $\begin{array}{l}\text { Paeonia suffruticosa } \\
\text { Andr. (Moutan Cortex) } \\
\text { Prunus persica L. Batsch } \\
\text { (Persicae Semen) }\end{array}$ & $10.0(23.8)$ \\
$\begin{array}{l}\text { Trichosanthes kirilowii Maxim } \\
\text { (Trichosanthis Fructus) }\end{array}$ & $10.0(23.8)$ \\
$\begin{array}{l}\text { Rheum plamatum L. } \\
\text { (Rhei Radix) }\end{array}$ & $10.0(23.8)$ \\
Mirabilite (Natrii Sulfas) & \\
Total & $6.0(14.3)$ \\
\hline
\end{tabular}

ELISA detection kits were purchased from R\&D Systems, Inc. (Minneapolis, MN, USA). Antibodies directed against iNOS (1:1,000; cat. no. sc-509), COX-2 (1:500; cat. no. sc-19999), IL-1ß (1:1,000; cat. no. sc-32294), p65 (1:500; cat. no. sc-109), ERK (1:1,000; cat. no. sc-154), p38 (1:1,000; cat. no. sc-535), IKK- $\alpha(1: 1,000$; cat. no. sc-1643), $\operatorname{IKK} \beta(1: 1,000$; cat. no.sc-8014), Akt (1:1,000; cat.no. sc-8312), lamin B (1:1,000; cat. no.sc-6216), $\beta$-actin (1:1,000; cat.no.sc-69879), goat anti-mouse IgG-horseradish peroxidase (HRP) (1:1,500; cat. no. sc-2005), goat anti-rabbit IgG-HRP (1:1,500; cat. no. sc-2004) and bovine anti-goat IgG-HRP (1:1,500; cat. no. sc-2350) were purchased from Santa Cruz Biotechnology, Inc. (Dallas, TX, USA). Anti- TNF- $\alpha$ (1:1,000; cat. no. 3707), phospho-JNK (1:500; cat. no. 9255), JNK (1:1,000; cat. no. 9252S), phospho-ERK (1:500; cat. no. 9106S), phospho-p38 (1:500; cat. no. 9211S), phospho-IKK $\alpha / \beta$ (1:50; cat. no. 2694) and p-Akt (1:500; cat. no. 9271) were purchased from Cell Signaling Technology Inc. (Danvers, MA, USA). All other chemicals were purchased from Sigma-Aldrich (Merck KGaA).

Preparation of the DHMDT extract. All herbs and mirabilite (natrii sulfas) (Table I) were obtained from Dongeui Oriental Hospital, Dongeui University College of Korean Medicine (Busan, South Korea). Each of the four herbal components of DHMDT and mirabilite were cut into small pieces and the components were then mixed together in the ratios shown in Table I to provide a total weight of $42 \mathrm{~g}$. The mixture was boiled with distilled water $(42 \mathrm{~g} / 500 \mathrm{ml})$ for $3 \mathrm{~h}$. The extract was filtered with a $0.45 \mu \mathrm{M}$ filter to remove insoluble materials. The filtrate was lyophilized and then crushed into a thin powder. The extracts were dissolved in dimethyl sulfoxide (DMSO) to a concentration of $100 \mathrm{mg} / \mathrm{ml}$, and the stock solution was then diluted with DMEM to the required concentration prior to use. The final concentration of DMSO was always $\leq 0.1 \%$.

Cell culture and LPS stimulation. Murine macrophage-like RAW 264.7 cells were obtained from the Korean Cell Line Bank (Seoul, South Korea) and grown in DMEM, supplemented with $10 \%$ FBS, glucose $(4.5 \mathrm{~g} / \mathrm{l})$, sodium pyruvate (1 mM), L-glutamine $(2 \mathrm{mM})$, penicillin $(100 \mathrm{U} / \mathrm{ml})$ and 
streptomycin $(100 \mathrm{U} / \mathrm{ml})$ in an incubator at $37^{\circ} \mathrm{C}$, with $5 \%$ $\mathrm{CO}_{2}$ and $95 \%$ humidity. To stimulate the cells, the medium was exchanged for fresh DMEM, and LPS (500 $\mathrm{ng} / \mathrm{ml})$ was added in the presence or absence of DHMDT for various time periods, as described in the following experiments.

Assessment of cell viability. The effects of DHMDT on cell viability were evaluated using an MTT assay. In brief, RAW 264.7 cells were seeded at a density of $1 \times 10^{4}$ cells/well in a 96 -well plate and incubated at $37^{\circ} \mathrm{C}$ for $24 \mathrm{~h}$, followed by treatment with $800 \mu \mathrm{g} / \mathrm{ml}$ DHMDT alone, $500 \mathrm{ng} / \mathrm{ml}$ LPS alone, or $500 \mathrm{ng} / \mathrm{ml}$ LPS plus 200, 400 or $800 \mu \mathrm{g} / \mathrm{ml}$ DHMDT for a further $24 \mathrm{~h}$. Untreated RAW 264.7 cells served as the control. Following this, MTT solution was added to each well and the plate was further incubated for $4 \mathrm{~h}$ at $37^{\circ} \mathrm{C}$. The medium was then discarded, and DMSO was added to dissolve the formazan dye. The optical density was then read at $450 \mathrm{~nm}$ using an ELISA reader (Infinite M200; Tecan Group, Ltd., Männedorf, Switzerland).

Measurement of NO production. The accumulation of NO was assayed using Griess reagent (1\% sulfanilamide, $0.1 \%$ naphthylethylenediamine dihydrochloride and $2.5 \%$ phosphoric acid). The cells were pretreated with 200,400 or $800 \mu \mathrm{g} / \mathrm{ml}$ DHMDT for $1 \mathrm{~h}$ and then stimulated with $500 \mathrm{ng} / \mathrm{ml}$ LPS for 24 h. Untreated RAW 264.7 cells served as the control group. Subsequently, $100 \mu \mathrm{l}$ Griess reagent was mixed with an equal volume of cell supernatant and the mixture was incubated at room temperature for $5 \mathrm{~min}$. The optical density at $540 \mathrm{~nm}$ was measured, and the concentration of nitrite was calculated according to the standard curve generated from known concentrations of sodium nitrite.

$P G E_{2}, T N F-\alpha$, and IL- $1 \beta$ immunoassay. The amounts of $\mathrm{PGE}_{2}$ and proinflammatory cytokines released in the culture medium were measured using mouse PGE 2 , TNF- $\alpha$ and IL-1 $\beta$ ELISA kits based on the quantitative sandwich enzyme immunosorbent technique. Pretreatment with DHMDT was conducted for $1 \mathrm{~h}$ prior to LPS stimulation for $24 \mathrm{~h}$, as described for the $\mathrm{NO}$ production assay. The levels of $\mathrm{PGE}_{2}, \mathrm{TNF}-\alpha$ and IL- $1 \beta$ in the culture media were quantified using ELISA kits according to the manufacturer's protocol. The absorbance was read at a wavelength of $450 \mathrm{~nm}$ using a microplate reader.

Western blot analysis. Following treatment with the various concentrations of DHMDT in the presence or absence of LPS, as described for the NO production assay, the cells were washed, scraped into cold PBS and centrifuged at $500 \mathrm{x} \mathrm{g}$ for $5 \mathrm{~min}$ at $4^{\circ} \mathrm{C}$. The cell pellets were suspended in lysis buffer [20 mM sucrose, $1 \mathrm{mM}$ EDTA, $20 \mu \mathrm{M}$ Tris- $\mathrm{HCl}$ (pH 7.2), $1 \mathrm{mM}$ dithiothreitol, $10 \mathrm{mM} \mathrm{KCl}, 1.5 \mathrm{mM} \mathrm{MgCl}_{2}$ and $5 \mu \mathrm{g} / \mathrm{ml}$ aprotinin]. Following removal of the cell debris by centrifugation at $13,000 \times \mathrm{g}$ for $15 \mathrm{~min}$ at $4^{\circ} \mathrm{C}$, the protein concentration was determined using Bio-Rad Protein Assay Dye Reagent Concentrate (Bio-Rad Laboratories, Inc., Hercules, CA, USA). In a parallel experiment, nuclear and cytosolic proteins were prepared using nuclear extraction reagents (Pierce; Thermo Fisher Scientific, Inc., Waltham, MA, USA) according to the manufacturer's protocol. Equal amounts of protein $(20-30 \mu \mathrm{g})$ from each sample were separated by $10 \%$ SDS-PAGE and transferred onto nitrocellulose membranes (Schleicher and Schuell; GE Healthcare Life Sciences, Little Chalfont, UK). Nonspecific sites were blocked by incubation of the membranes for $1 \mathrm{~h}$ at room temperature with 5\% (w/v) non-fat milk powder in Tris-buffered saline containing $0.05 \%$ (v/v) Tween-20. Thereafter, the membranes were incubated overnight at $4^{\circ} \mathrm{C}$ with the corresponding primary antibodies and subsequently incubated with the appropriate HRP-conjugated secondary antibodies for $1 \mathrm{~h}$ at room temperature. The specific proteins were detected using an Amersham ECL Western Blotting Detection Reagent (Amersham; GE Healthcare Life Sciences). Densitometric analyses were completed using the ImageJ software (version 1.50i; National Institutes of Health, Bethesda, MD, USA) to quantify protein expression levels. All protein measurements were normalized to $\beta$-actin expression and these normalized values were used for all statistical analyses.

Immunofluorescent staining of $N F-\kappa B$ p65. RAW 264.7 cells were seeded on glass coverslips in 6-well plates for $24 \mathrm{~h}$. The cells were then treated with DHMDT (200-800 $\mu \mathrm{g} / \mathrm{ml})$ for $1 \mathrm{~h}$, followed by stimulation with $500 \mathrm{ng} / \mathrm{ml}$ LPS for $30 \mathrm{~min}$. Untreated RAW 264.7 cells served as the control. The cells were then rinsed twice with PBS and fixed with $3.7 \%$ paraformaldehyde in PBS for $10 \mathrm{~min}$ at $4^{\circ} \mathrm{C}$. Following fixation, the cells were incubated with $0.4 \%$ Triton X-100 for $10 \mathrm{~min}$ and blocked with $5 \%$ bovine serum albumin (Sigma-Aldrich; Merck $\mathrm{KGaA}$ ) for $1 \mathrm{~h}$ at room temperature, followed by probing with rabbit anti-p65 NF- $\kappa$ B antibody (1:50; cat. no. sc-109; Santa Cruz Biotechnology, Inc.) overnight at $4^{\circ} \mathrm{C}$. The cells were then incubated with fluorescein isothiocyanate-conjugated donkey anti-rabbit IgG (1:200; cat. no. 711-095-152; Jackson ImmunoResearch Laboratories, Inc., West Grove, PA, USA) for $2 \mathrm{~h}$ at room temperature. After washing with PBS, the nuclei were counterstained with DAPI solution $(1 \mathrm{mg} / \mathrm{ml})$ for $15 \mathrm{~min}$ in the dark, and fluorescence was visualized using a fluorescence microscope (Carl Zeiss AG, Oberkochen, Germany).

Statistical analysis. Data from at least three independent experiments are expressed as the mean \pm standard deviation (SD). Differences among the groups were evaluated using one-way analysis of variance followed by Duncan's multiple range tests. The statistical analysis was conducted using SPSS 19.0 software (IBM Corp., Armonk, NY, USA). P<0.05 was considered to indicate a statistically significant difference.

\section{Results}

Inhibition of the LPS-induced production of $N O$ and $P G E_{2}$ by DHMDT in RAW 264.7 macrophages. The potential inhibitory effects of DHMDT on LPS-induced NO and $\mathrm{PGE}_{2}$ production in RAW 264.7 macrophages were first examined using Griess reagent and ELISA analyses, respectively. The cells were pretreated with various concentrations of DHMDT for $1 \mathrm{~h}$ prior to stimulation with $500 \mathrm{ng} / \mathrm{ml} \mathrm{LPS} \mathrm{for} 24 \mathrm{~h}$. As illustrated in Fig. 1, $\mathrm{NO}$ and $\mathrm{PGE}_{2}$ production was significantly induced in the LPS-stimulated RAW 264.7 cells compared with the unstimulated negative control, and pretreatment with DHMDT significantly prevented this increase in a dose-dependent manner. To exclude the possibility of DHMDT having a 
A

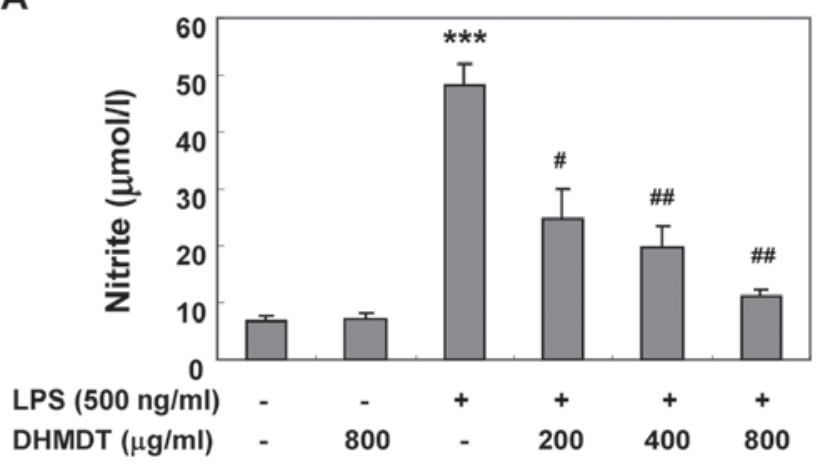

B

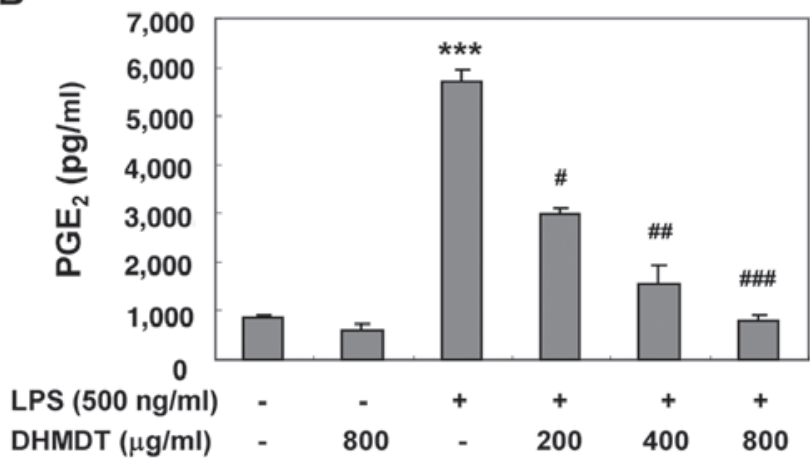

Figure 1. Inhibition of $\mathrm{NO}$ and $\mathrm{PGE}_{2}$ production by DHMDT in LPS-stimulated RAW 264.7 macrophages. The RAW 264.7 cells were pretreated with various concentrations (200-800 $\mu \mathrm{g} / \mathrm{ml})$ of DHMDT for $1 \mathrm{~h}$ prior to incubation with LPS $(500 \mathrm{ng} / \mathrm{ml})$ for $24 \mathrm{~h}$. (A) The nitrite content was measured with the Griess reaction. (B) The $\mathrm{PGE}_{2}$ concentration was measured in culture media using a commercial ELISA kit. Each value indicates the mean \pm standard deviation and is representative of the results obtained from three independent experiments. ${ }^{* * * *} \mathrm{P}<0.001$ vs. the untreated control; ${ }^{*} \mathrm{P}<0.05$, ${ }^{\# \#} \mathrm{P}<0.01$ and ${ }^{\# \# \#} \mathrm{P}<0.001$ vs. cells cultured with $500 \mathrm{ng} / \mathrm{ml}$ LPS only. NO, nitric oxide; $\mathrm{PGE}_{2}$, prostaglandin $\mathrm{E}_{2}$; DHMDT, Daehwangmokdantang; LPS, lipopolysaccharide.

cytotoxic effect on the RAW 264.7 cells, the viability of the cells was evaluated using an MTT assay. The concentrations (200, 400 and $800 \mu \mathrm{g} / \mathrm{ml}$ ) used for the inhibition of NO and $\mathrm{PGE}_{2}$ production did not exhibit any cytotoxicity (Fig. 2), confirming that inhibition of $\mathrm{NO}$ and $\mathrm{PGE}_{2}$ production in the LPS-stimulated RAW 264.7 cells was not due to a cytotoxic action of DHMDT.

Inhibition of the LPS-induced expression of $i N O S$ and COX-2 by DHMDT in RAW 264.7 macrophages. To further investigate the mechanism of the inhibitory effect of DHMDT on NO and $\mathrm{PGE}_{2}$ production, the protein expression of iNOS and COX-2, the enzymes that mediate the synthesis of $\mathrm{NO}$ and $\mathrm{PGE}_{2}(9,10)$, was determined using western blot analysis. As shown in Fig. 3, the protein levels of iNOS and COX-2 were undetectable in the RAW 264.7 cells in the absence of LPS stimulation, and treatment with LPS alone significantly increased iNOS and COX-2 protein levels. However, the pretreatment with DHMDT significantly suppressed the expression of iNOS and COX-2 proteins. These results indicate that DHMDT was able to inhibit the expression of iNOS and COX-2 enzymes, which, in turn, reduced the production of $\mathrm{NO}$ and $\mathrm{PGE}_{2}$, two key mediators of inflammation.

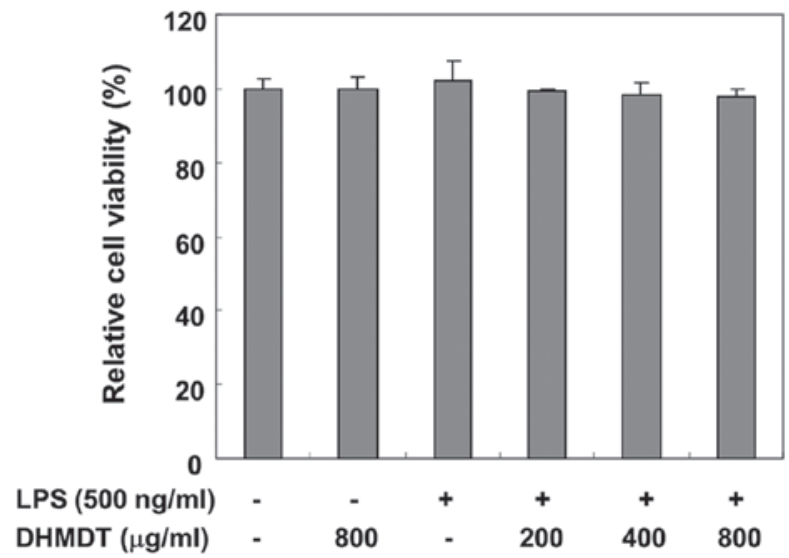

Figure 2. Effect of DHMDT on the cell viability of RAW 264.7 macrophages. The cells were treated with the indicated concentrations of DHMDT for $1 \mathrm{~h}$ prior to LPS $(500 \mathrm{ng} / \mathrm{ml})$ treatment for $24 \mathrm{~h}$. The cell viability was assessed with an MTT reduction assay, and the results are expressed as the percentage of surviving cells over untreated control cells. Each value indicates the mean \pm standard deviation and is representative of the results obtained from three independent experiments. LPS, lipopolysaccharide; DHMDT, Daehwangmokdantang.
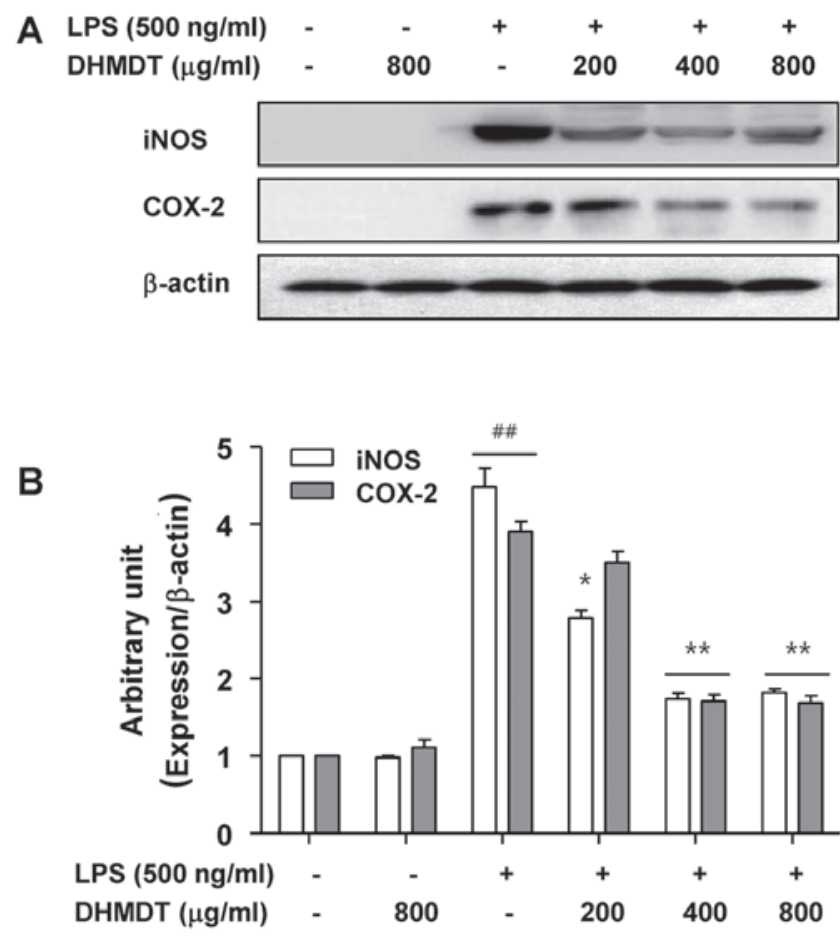

Figure 3. Inhibition of iNOS and COX-2 expression by DHMDT in LPS-stimulated RAW 264.7 macrophages. The RAW 264.7 cells were pretreated with DHMDT for $1 \mathrm{~h}$ prior to incubation with LPS for $24 \mathrm{~h}$. (A) Cell lysates were then prepared, and western blotting was performed using antibodies specific for murine iNOS and COX-2. $\beta$-actin was used as an internal control for western blot analysis. (B) ImageJ densitometric analysis of bands expressed in relation to $\beta$-actin. Data are presented as mean \pm standard deviation of the mean. ${ }^{\# \#} \mathrm{P}<0.01$ vs. the untreated control; ${ }^{*} \mathrm{P}<0.05$ and ${ }^{* * *} \mathrm{P}<0.01$ vs. cells cultured with $500 \mathrm{ng} / \mathrm{ml}$ LPS only. iNOS, inducible nitric oxide synthase; COX, cyclooxygenase; DHMDT, Daehwangmokdantang; LPS, lipopolysaccharide.

Inhibition of the LPS-induced production and expression of TNF- $\alpha$ and IL-1 $\beta$ by DHMDT in RAW 264.7 macrophages. To examine the effects of DHMDT on the production of proinflammatory cytokines following LPS treatment, the levels of 
A

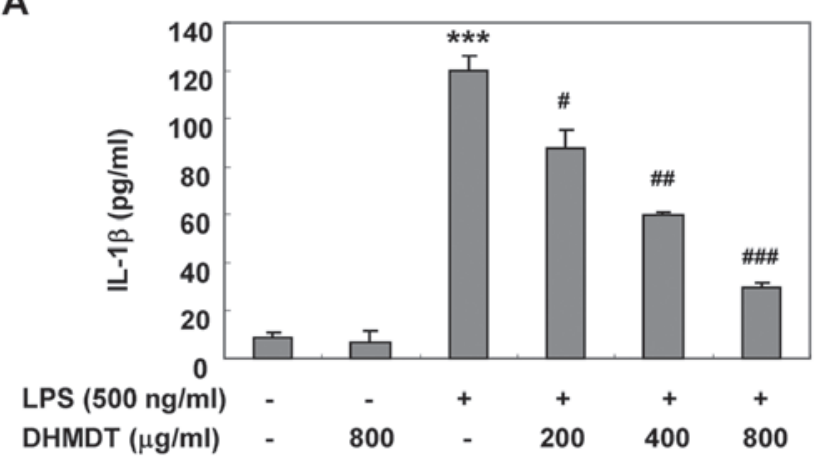

B

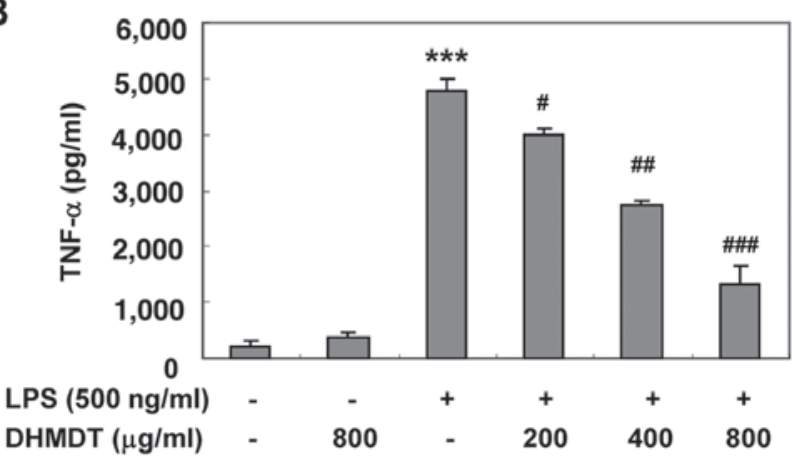

Figure 4. Effect of DHMDT on LPS-stimulated TNF- $\alpha$ and IL-1 $\beta$ production in RAW 264.7 macrophages. The RAW 264.7 cells were pretreated with DHMDT for $1 \mathrm{~h}$ prior to the LPS treatment. Following incubation for $24 \mathrm{~h}$, the levels of (A) IL-1 $\beta$ and (B) TNF- $\alpha$ present in the supernatants were measured. Each value indicates the mean \pm standard deviation and is representative of the results obtained from three independent experiments. ${ }^{* * *} \mathrm{P}<0.001 \mathrm{vs}$. the untreated control; ${ }^{\#} \mathrm{P}<0.05$, ${ }^{\# \#} \mathrm{P}<0.01$ and ${ }^{\# \# \#} \mathrm{P}<0.001$ vs. cells cultured with 500 ng/ml LPS only. DHMDT, Daehwangmokdantang; LPS, lipopolysaccharide; TNF, tumor necrosis factor; IL, interleukin.

TNF- $\alpha$ and IL-1 $\beta$ in the culture media were measured using an ELISA. As shown in Fig. 4, the challenge with LPS alone induced significant increases in the levels of TNF- $\alpha$ and IL-1 $\beta$, whereas the pretreatment with DHMDT significantly reduced the secretion of TNF- $\alpha$ and IL-1 $\beta$ in the cell media in a concentration-dependent manner. Next, whether the inhibitory effect of DHMDT on TNF- $\alpha$ and IL- $1 \beta$ release into the culture medium was associated with modulation of the protein levels in the RAW 264.7 cells was investigated using western blotting. As shown in Fig. 5, DHMDT significantly suppressed the protein expression of TNF- $\alpha$ and IL- $1 \beta$ compared with that in the LPS only-treated group. The reduced expression of the TNF- $\alpha$ and IL-1 $\beta$ proteins was consistent with the reduction in $\mathrm{NO}$ and $\mathrm{PGE}_{2}$ in the culture media, suggesting that the DHMDT-mediated inhibition of TNF- $\alpha$ and IL- $1 \beta$ production is associated with the downregulation of TNF- $\alpha$ and IL-1 $\beta$ expression.

Attenuation of the LPS-induced nuclear translocation of $N F-\kappa B$ by DHMDT in RAW 264.7 macrophages. As NF- $\kappa \mathrm{B}$ plays a pivotal role in the regulation of iNOS, COX-2 and proinflammatory cytokine expression $(11,12)$, the effects of DHMDT on the activation of $\mathrm{NF}-\kappa \mathrm{B}$ were examined. As displayed in Fig. 6A, LPS stimulation for $30 \mathrm{~min}$ caused the translocation of $\mathrm{p} 65$, a component of the heterodimer of $\mathrm{NF}-\kappa \mathrm{B}$, to the nucleus. However, DHMDT pretreatment
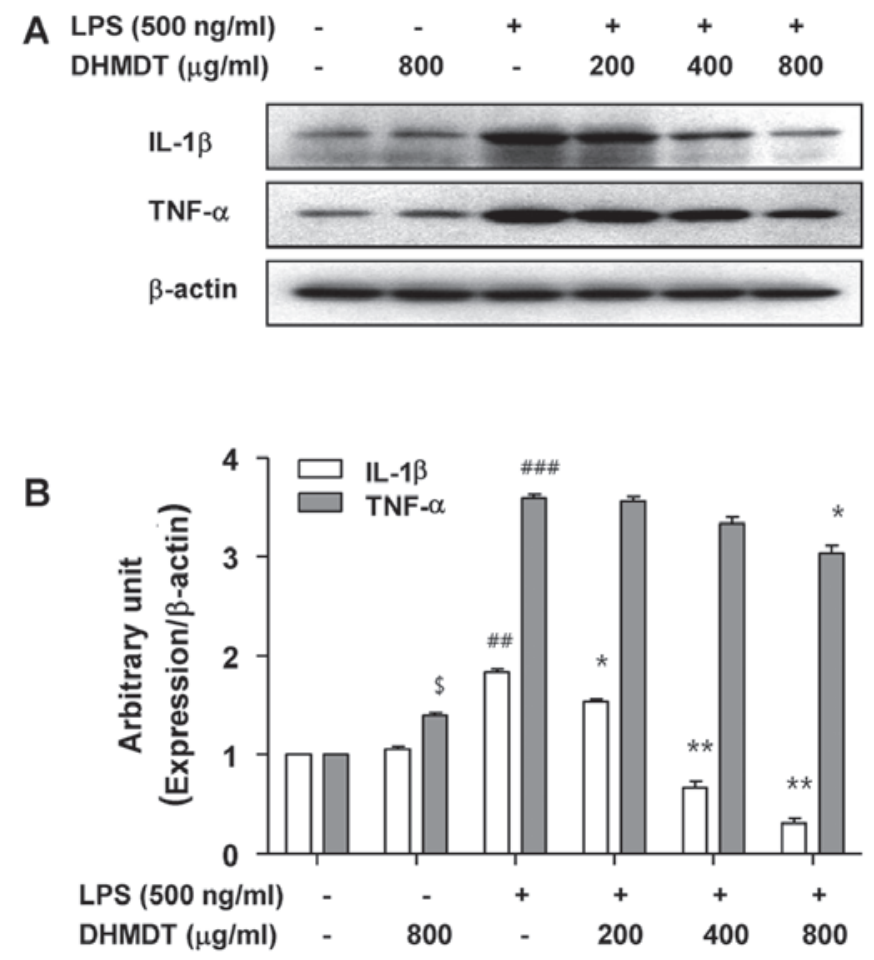

Figure 5. Effect of DHMDT on LPS-stimulated TNF- $\alpha$ and IL-1 $\beta$ expression in RAW 264.7 macrophages. The RAW 264.7 cells were pretreated with DHMDT for $1 \mathrm{~h}$ prior to incubation with LPS for $24 \mathrm{~h}$. (A) Cell lysates were then prepared, and western blotting was performed using antibodies specific for murine TNF- $\alpha$ and IL-1 $\beta$. $\beta$-actin was used as an internal control for western blot analysis. (B) ImageJ densitometric analysis of bands expressed in relation to $\beta$-actin. Data are presented as mean \pm standard deviation of the mean. ${ }^{\$} \mathrm{P}<0.05,{ }^{\# \#} \mathrm{P}<0.01$ and ${ }^{\# \# \#} \mathrm{P}<0.005$ vs. the untreated control; ${ }^{*} \mathrm{P}<0.05$ and ${ }^{* *} \mathrm{P}<0.01$ vs. cells cultured with $500 \mathrm{ng} / \mathrm{ml}$ LPS only. DHMDT, Daehwangmokdantang; LPS, lipopolysaccharide; TNF, tumor necrosis factor; IL, interleukin.

effectively blocked the LPS-induced nuclear accumulation of p65 in the cells. These results were confirmed by NF- $\mathrm{BB}$ and DAPI co-staining in the LPS-treated RAW 264.7 cells, with DHMDT significantly preventing the nuclear translocation of p65 (Fig. 6B). As the phosphorylation of IкB kinase (IKK) $\alpha / \beta$ allows I $\mathrm{B} \alpha$ to be phosphorylated and ubiquitinated from the p50/p65 complex of NF- $\mathrm{B}$, the effects of DHMDT on the inhibition of IKK activity in the RAW 264.7 cells were explored. The western blotting data reveal that DHMDT inhibited the LPS-induced phosphorylation of IKK $\alpha / \beta$ (Fig. 7A), suggesting that DHMDT effectively inhibits LPS-induced NF- $\kappa$ B pathway activation by blocking the nuclear translocation of NF- $\mathrm{NB}$ and the phosphorylation of IKK $\alpha / \beta$.

Suppression of the LPS-induced phosphorylation of AKT and MAPKs by DHMDT in RAW 264.7 macrophages. To investigate whether the inhibition of inflammatory reactions by DHMDT was mediated through the PI3K/Akt and MAPK pathways, the effects of DHMDT on LPS-induced phosphorylation of upstream kinases, including Akt, ERK, JNK, and p38 MAPK in the RAW 264.7 cells were examined. As shown in Fig. 7, the phosphorylated levels of Akt and the three MAPKs were significantly increased following treatment for $30 \mathrm{~min}$ in the LPS-stimulated cell group, compared with the control group without LPS treatment. DHMDT pretreatment 
A

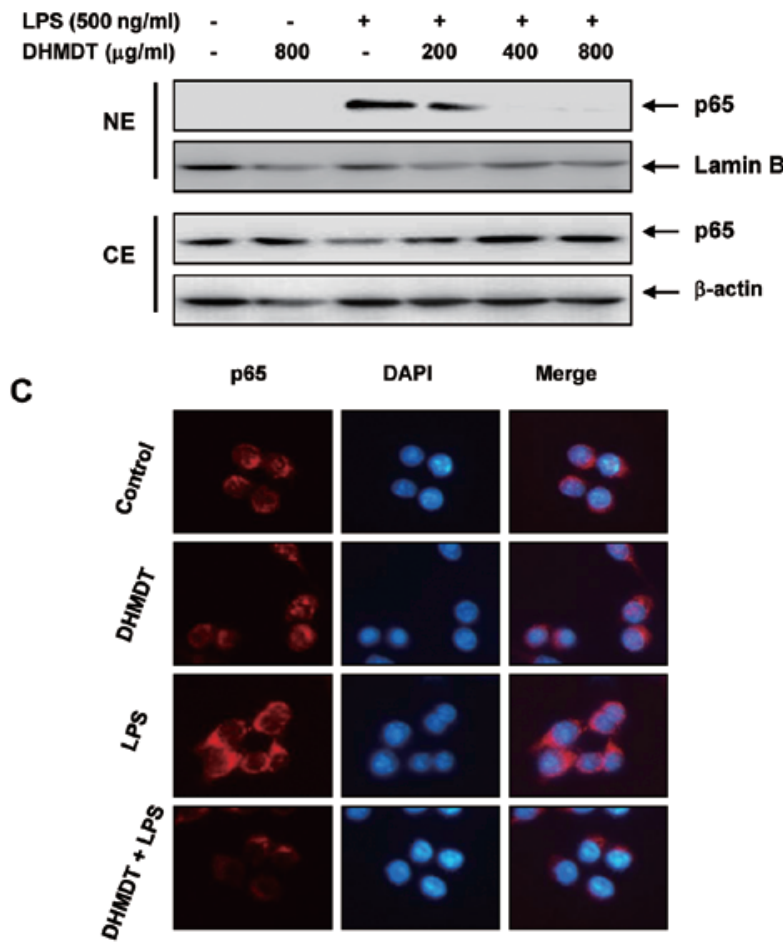

B

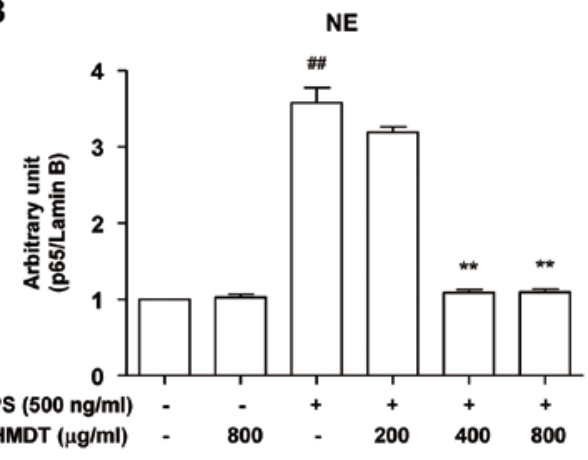

CE

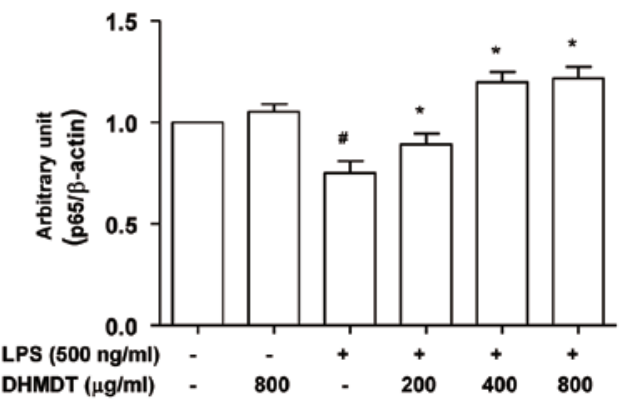

Figure 6. Effect of DHMDT on LPS-induced NF-кB nuclear translocation in RAW 264.7 macrophages. The cells were treated with the indicated concentrations of DHMDT for $1 \mathrm{~h}$ prior to treatment with $500 \mathrm{ng} / \mathrm{ml} \mathrm{LPS} \mathrm{for} 30 \mathrm{~min}$. (A) Nuclear and cytosolic proteins were subjected to $10 \%$ SDS-PAGE, followed by western blotting using anti-NF-kB p65 antibody. Lamin B and $\beta$-actin were used as internal controls for the nuclear and cytosolic fractions, respectively. (B) ImageJ densitometric analysis of bands expressed in relation to lamin B and $\beta$-actin. Data are presented as mean \pm standard deviation of the mean. ${ }^{\#} \mathrm{P}<0.05$ and ${ }^{\# \#} \mathrm{P}<0.01$ vs. the untreated control; ${ }^{*} \mathrm{P}<0.05$ and ${ }^{* *} \mathrm{P}<0.01$ vs. cells cultured with $500 \mathrm{ng} / \mathrm{ml} \mathrm{LPS}$ only. (C) The cells were pretreated with $800 \mu \mathrm{g} / \mathrm{ml}$ of DHMDT for $1 \mathrm{~h}$ prior to stimulation with LPS for $30 \mathrm{~min}$. Localization of NF-kB p65 was visualized with a fluorescence microscope following immunofluorescence staining with anti-NF-kB p65 antibody (red) and staining with DAPI for the visualization of nuclei (blue). Magnification, x400. DHMDT,

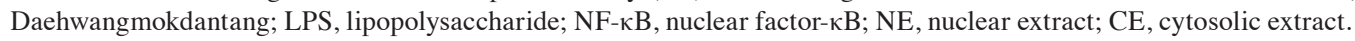

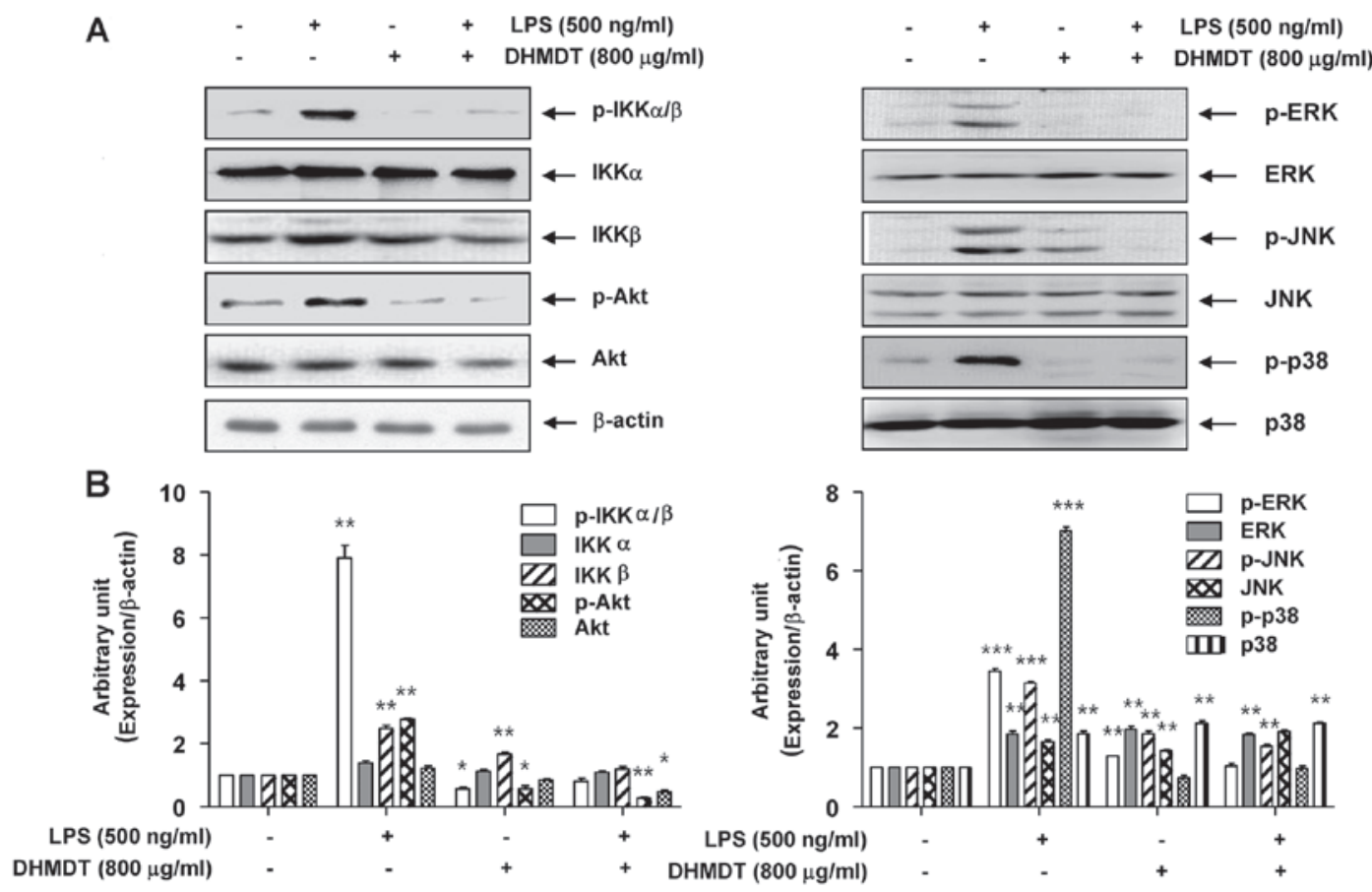

Figure 7. Effect of DHMDT on the LPS-induced phosphorylation of IKK $\alpha / \beta$, Akt and MAPKs in RAW 264.7 macrophages. The RAW 264.7 cells were pretreated with $800 \mu \mathrm{g} / \mathrm{ml}$ DHMDT for $1 \mathrm{~h}$ prior to exposure to LPS for $30 \mathrm{~min}$, and total proteins were isolated. (A) The proteins were subjected to SDS-PAGE, followed by western blot analysis. (B) ImageJ densitometric analysis of bands expressed in relation to $\beta$-actin. Data are presented as mean \pm standard deviation of the mean. ${ }^{*} \mathrm{P}<0.05,{ }^{* *} \mathrm{P}<0.01$ and ${ }^{* * *} \mathrm{P}<0.005$ vs. cells cultured with $500 \mathrm{ng} / \mathrm{ml}$ LPS only. DHMDT, Daehwangmokdantang; LPS, lipopolysaccharide; p-, phosphorylated; IKK, inhibitor of nuclear factor-кB kinase; Akt, protein kinase B; ERK, extracellular signal-regulated kinase; JNK, c-Jun NH2-terminal kinase. 
clearly attenuated the phosphorylation levels of these kinases compared with those in the LPS only-treated group. These results suggest that the anti-inflammatory effect of DHMDT may be due to modulation of the PI3K/Akt and MAPK signaling pathways in RAW 264.7 macrophages.

\section{Discussion}

Macrophages are an important component in the immune defense mechanism. Under normal circumstances, inflammation-associated mediators, including $\mathrm{NO}$ and $\mathrm{PGE}_{2}$, which are generated by iNOS and COX-2 enzymes, respectively, and cytokines generated from macrophages have an essential role in host survival and tissue repair $(3,16)$. However, these inflammatory mediators and cytokines are overproduced in response to stimuli and may cause inflammation-associated disorders $(4,17)$. Moreover, proinflammatory cytokines, including TNF- $\alpha$ and IL-1 $\beta$, evoke increases in the levels of iNOS and COX-2, followed by significant increases in NO and $\mathrm{PGE}_{2}$ production $(1,2)$. Therefore, investigation of the suppression of $\mathrm{NO}$ and $\mathrm{PGE}_{2}$ via the inhibition of iNOS and COX-2 is important in the development of anti-inflammatory agents. The results of the present study demonstrated that LPS significantly upregulated the production of $\mathrm{NO}$ and $\mathrm{PGE}_{2}$, and that pretreatment with DHMDT significantly inhibited the LPS-induced release of $\mathrm{NO}$ and $\mathrm{PGE}_{2}$ by the RAW 264.7 macrophages, with no cytotoxicity at the concentrations employed. In addition, the results from the western blot analysis revealed that the application of DHMDT reduced the LPS-induced iNOS and COX-2 levels, and ELISA results demonstrated that DHMDT dose-dependently inhibited LPS-induced TNF- $\alpha$ and IL-1 $\beta$ production by the RAW 264.7 macrophages. Consistent with these findings, it was observed that DHMDT significantly suppressed the protein levels of TNF- $\alpha$ and IL-1 $\beta$. The results of the present study suggest that DHMDT may elicit anti-inflammatory effects in RAW 264.7 macrophages by reducing the LPS-stimulated production of proinflammatory molecules.

$\mathrm{NF}-\kappa \mathrm{B}$ is a critical inducible transcription factor, which serves a major role in the regulation of gene expression in response to inflammation $(11,12)$. The activation of $\mathrm{NF}-\kappa \mathrm{B}$ involves phosphorylation and subsequent proteolytic degradation of the inhibitory protein $\mathrm{I} \kappa \mathrm{B} \alpha$, which binds to the $\mathrm{NF}-\kappa \mathrm{B}$ complex in the cytoplasm. Free $\mathrm{NF}-\kappa \mathrm{B}$ is then translocated into the nucleus, where it binds to the $\mathrm{NF}-\kappa \mathrm{B}$ site in the promoter regions of genes for inflammatory proteins, including iNOS, COX-2, TNF- $\alpha$, and IL-1 $\beta$. The engagement of LPS activates IKK, which initiates signal-induced degradation of I $\mathrm{B}$ proteins. IKK phosphorylates $\mathrm{I} \kappa \mathrm{B} \alpha$ and then ubiquitinates $\mathrm{p}-\mathrm{I} \kappa \mathrm{B} \alpha$ from NF- $\kappa \mathrm{B}$, which enables the translocation of $\mathrm{NF}-\kappa \mathrm{B}$ into the nucleus $(8,16)$. To investigate whether the inhibitory effect of DHMDT on the production and expression of proinflammatory factors was associated with $\mathrm{NF}-\kappa \mathrm{B}$ pathway activity, the effect of DHMDT on NF- $\kappa$ B nuclear translocation was measured in the present study. The results indicated that LPS alone reduced the levels of NF- $\mathrm{B}$ p65 in the cytoplasm of the RAW 264.7 macrophages and increased those in the nucleus, and that this effect was reversible by pretreatment with DHMDT. Furthermore, additional evidence that the inhibition of NF- $\kappa \mathrm{B}$ nuclear translocation by DHMDT resulted from the disturbance of IKK $\alpha / \beta$ activation was obtained. The present study demonstrated that DHMDT prevented the LPS-induced phosphorylation of IKK $\alpha / \beta$ in RAW 264.7 macrophages. This suggests that inhibition of the NF- $\mathrm{B}$ signaling pathway by the suppression of IKK activation in RAW 264.7 macrophages may regulate the suppressive effects of DHMDT on inflammatory mediators and cytokines.

Although the role of PI3K/Akt signaling in the regulation of NF- $\kappa \mathrm{B}$ transactivation is unclear, studies have shown that phosphorylated Akt promotes the liberation of $\mathrm{NF}-\kappa \mathrm{B}$ upon the activation of Akt by $\mathrm{PI} 3 \mathrm{~K}$ and that $\mathrm{NF}-\kappa \mathrm{B}$ subsequently translocates into the cell nucleus to transcribe inflammatory mediators $(13,14)$. By inducing the nuclear translocation of p65 in macrophages, the MAPK pathway activates pathways leading to the production of proinflammatory mediators and cytokines $(18,19)$. Therefore, PI3K/Akt- and MAPK-targeted therapeutics may be effective for the treatment of inflammatory diseases, given that a wide variety of pharmacological agents reportedly inhibit activation steps in the PI3K/Akt and MAPK signaling pathways $(8,20)$. To investigate whether the anti-inflammatory effects of DHMDT were mediated through the PI3K/Akt and MAPK pathways, the LPS-induced phosphorylation of Akt and various MAPK family proteins, specifically ERK, JNK and p38 MAPK, were assessed in the present study. DHMDT pretreatment was observed to markedly suppress the LPS-stimulated phosphorylation of Akt, which is a critical step in PI3K activation $(7,8)$. Additionally, DHMDT significantly inhibited the LPS-induced phosphorylation of three MAPKs. These results indicate that DHMDT blocks LPS-induced $\mathrm{NF}-\kappa \mathrm{B}$ activation via changes in the phosphorylation of Akt and MAPKs. In particular, inhibition of the phosphorylation of Akt or MAPKs may lead to reductions in the production and expression levels of inflammatory enzymes, including iNOS and COX-2, and cytokines in RAW 264.7 macrophages.

In conclusion, the results of the present study indicate that DHMDT has a strong inhibitory effect on the secretion of $\mathrm{NO}, \mathrm{PGE}_{2}$ and inflammatory cytokines, including TNF- $\alpha$ and IL-1 $\beta$. In the LPS-stimulated RAW 264.7 macrophages, this inhibitory effect was exerted via suppression of iNOS, COX-2, TNF-a and IL-1b protein expression. These inhibitory effects are possibly mediated by the inhibition of $\mathrm{NF}-\kappa \mathrm{B}$ activation and blockade of the PI3K/Akt and MAPK signaling pathways.

Although further studies are warranted to establish the signaling pathways responsible for the observed effects, the results of the present study suggest that DHMDT may be a useful agent for the prevention or reversal of inflammatory responses.

\section{Acknowledgements}

The present study was supported by Basic Science Research Program through the National Research Foundation of Korea (NRF) grant funded by the Korea government (grant nos. 2013R1A1A2065537 and 2015R1A2A2A01004633).

\section{References}

1. Conti B, Tabarean I, Andrei C and Bartfai T: Cytokines and fever. Front Biosci 9: 1433-1449, 2004

2. Amin AR, Attur M and Abramson SB: Nitric oxide synthase and cyclooxygenases: Distribution, regulation, and intervention in arthritis. Curr Opin Rheumatol 11: 202-209, 1999. 
3. Zhang X and Mosser DM: Macrophage activation by endogenous danger signals. J Pathol 214: 161-178, 2008.

4. Muralidharan S and Mandrekar P: Cellular stress response and innate immune signaling: Integrating pathways in host defense and inflammation. J Leukoc Biol 94: 1167-1184, 2013.

5. Verstrepen L, Adib-Conquy M, Kreike M, Carpentier I, Adrie C, Cavaillon JM and Beyaert R: Expression of the NF-kappaB inhibitor ABIN-3 in response to TNF and toll-like receptor 4 stimulation is itself regulated by NF-kappaB. J Cell Mol Med 12: 316-329, 2008

6. Buchanan MM, Hutchinson M, Watkins LR and Yin H: Toll-like receptor 4 in CNS pathologies. J Neurochem 114: 13-27, 2010.

7. Li L, Jacinto R, Yoza B and McCall CE: Distinct post-receptor alterations generate gene- and signal-selective adaptation and cross-adaptation of TLR4 and TLR2 in human leukocytes. J Endotoxin Res 9: 39-44, 2003

8. Broom OJ, Widjaya B, Troelsen J, Olsen J and Nielsen $\mathrm{OH}$ Mitogen activated protein kinases: A role in inflammatory bowel disease? Clin Exp Immunol 158: 272-280, 2009.

9. del Zoppo G, Ginis I, Hallenbeck JM, Iadecola C, Wang X and Feuerstein GZ: Inflammation and stroke: Putative role for cytokines, adhesion molecules and iNOS in brain response to ischemia. Brain Pathol 10: 95-112, 2000.

10. McDaniel ML, Kwon G, Hill JR, Marshall CA and Corbett JA Cytokines and nitric oxide in islet inflammation and diabetes. Proc Soc Exp Biol Med 211: 24-32, 1996.

11. Li Q and Verma IM: NF-kappaB regulation in the immune system. Nat Rev Immunol 2: 725-734, 2002.

12. Yenari MA and Han HS: Influence of hypothermia on post-ischemic inflammation: Role of nuclear factor kappa B (NFkappaB) Neurochem Int 49: 164-169, 2006.
13. Caivano M: Role of MAP kinase cascades in inducing arginine transporters and nitric oxide synthetase in RAW264 macrophages. FEBS Lett 429: 249-253, 1998.

14. Li X, Jiang S and Tapping RI: Toll-like receptor signaling in cell proliferation and survival. Cytokine 49: 1-9, 2010.

15. Heo J and Kim KJ (eds): Dongui Bogam. Beopinmunhwasa Publishing Corp., Seoul, 1999 (In Korean).

16. Fujihara M, Muroi M, Tanamoto K, Suzuki T, Azuma H and Ikeda $\mathrm{H}$ : Molecular mechanisms of macrophage activation and deactivation by lipopolysaccharide: Roles of the receptor complex. Pharmacol Ther 100: 171-194, 2003.

17. Laveti D, Kumar M, Hemalatha R, Sistla R, Naidu VG, Talla V, Verma V, Kaur N and Nagpal R: Anti-inflammatory treatments for chronic diseases: A review. Inflamm Allergy Drug Targets 12: 349-361, 2013.

18. Haddad JJ: The role of inflammatory cytokines and NF-kappaB/MAPK signaling pathways in the evolution of familial Mediterranean fever: Current clinical perspectives and potential therapeutic approaches. Cell Immunol 260: 6-13, 2009.

19. Saklatvala J: Inflammatory signaling in cartilage: MAPK and NF-kappaB pathways in chondrocytes and the use of inhibitors for research into pathogenesis and therapy of osteoarthritis. Curr Drug Targets 8: 305-313, 2007.

20. Wei J and Feng J: Signaling pathways associated with inflammatory bowel disease. Recent Pat Inflamm Allergy Drug Discov 4: 105-117, 2010. 